\title{
In the search for the 'Smart' Source of the Citizen's Perception of Quality of Life in European Smart Cities
}

\author{
Manuel Pedro Rodríguez Bolívar \\ University of Granada, Spain \\ manuelp@ugr.es
}

\begin{abstract}
In the last years, cities are actively developing strategies towards the goal of becoming "smart" with the promise of producing a higher quality of life (QLF) for citizens in the urban environment. This paper seeks to analyze whether smart cities are those with a higher QLF in the urban environment as well as to investigate the smart dimensions that could have an influence on the citizen's perception of QLF. Findings based on a sample of European smart cities indicate that the smart city's promise of increasing the citizen's QLF is true, but it seems to be mainly focused on the outcomes (smart living dimension) and not in other smart dimensions that could be focused on the process to obtain the outcomes (smart governance or smart environment, for example).
\end{abstract}

\section{Introduction}

The current dynamics of European urban systems cannot be interpreted through the advances of urban size but calls for an interpretation of urban dynamics through a different conceptualization of agglomeration economies based on the urban economic theory dealing with increasing/decreasing returns to urban size [12]. Under this framework, the creation of public value has become the main goal of public organizations [9], which has made public administration to go beyond the pursuit of efficiency towards the generation of common values that citizens and other stakeholders' desire [52] with the active help of co-producers and partner organizations [6].

In the last decade, the quality of life (QLF), the economic, knowledge and human capitals' development have been identified as the main challenges of the new wave of cities [34]. These key urban dimensions, especially those in the social and economic sphere $[7,5]$, are exerting their pressure on the city dynamics locally, typically bottom-up occurrences, and are tightly linked with accelerating wealth creation and faster innovation cycles [7]. By this way, cities are in disequilibrium, being innovation and technological changes that condition their dynamic entirely [5].

In this context, at the end of the 1990s, different initiatives for the implementation of the information and communication technologies (ICTs) in the urban space allowed the origin of the term "Smart City" (SC), as a first attempt to use the great potential that ICTs offer to support local democracy and to deliver efficient public services [2]. This latest wave of the emerging new systemic interpretations of the city may be traced to both the evolution of public value [28] and the implementation of ubiquitous ICTs [24].

Although there remains some lack of clarity over what public value is [52], taking into account the need of interaction with the environment for identifying the society expectations $[17,18,40]$, the need of information transparency [18] and the higher level of citizen participation in public affairs for increasing public value [33], in this paper public value creation must be understood as a strategic approach to public management based on the promotion of networked governance [37] with the aim at improving the citizen's QLF.

In fact, the concept of public value begins as an abstract philosophical idea that the job of the public execution is to use public assets to improve the quality of life at individual and collective levels [38] through democratic governance [37]. This way, with mission alignment with values articulated by citizens and the engagement of citizens as co-producers, both embedded within the legitimacy and support perspective of the public value chain defined by Moore [37], public administrations can increase the QLF through citizen satisfaction and the achievement of social outcomes $[37,8]$, mainly with the use of new technologies into the SC's framework [49].

Also, based on the post-material position combined with a technocratic perspective on good governance, public values in SC are produced through innovative collaboration [35] and are intended to improve the citizen's QLF in the municipality [34, 21], influencing on the different aspects of the city life [43]. Therefore, 
public value management situates public organizations in a wider network of stakeholders who have to be involved in the public value creation [52, 37], in which the use of smart solutions becomes the main goal for improving the quality life $[48,4,10]$.

Consequently, public managers must focus on the identification and measurement of the elements necessary to create public value [47], which is the result of aligning three interrelated processes in a strategic triangle [36]: (1) defining public value, (2) building and sustaining a group of diverse stakeholders to create an authorizing environment, and (3) mobilizing the resources from inside and outside the organization to achieve the desired outcomes. Nonetheless, despite the relevance of public value creation, the most striking feature in the public value literature is the relative absence of empirical investigation of either the normative propositions of public value or its efficacy as a framework for understanding public management [52]. As noted previously, the public value approach is understood as the framework for increasing the QLF in the urban environment and, by this way, this paper tries to fill the gap for understanding whether the SC framework allows a higher QLF. The first question here is:

RQ1. How is the transition possible from the objective measures of city smartness to an intangible entity of QLF?.

On another hand, the concept of the smart city is a wide, fuzzy and complex concept [50, 42]. In general, it is assumed that smart cities involve the extensive and intensive application of ICT to several spheres of functioning in a city and not focusing on a single aspect, which makes necessary to identify certain characteristics of the cities for their evaluation with a ranking methodology [26]. In this regard, nowadays, it is generally recognized that SCs can be identified by six main characteristics or smart dimensions -smart economy, smart people, smart governance, smart mobility, smart environment, and smart living- [26]. These dimensions are also valid for analyzing the QLF. In fact, although Eurostat and representatives of the EU Member States have designed an overarching framework for analyzing the QLF through eight dimensions, which feed into the measurement of the overall experience of life [19], these dimensions can be identified with, at least, five of the smart dimensions of SCs (all of them except for smart mobility). In particular, these dimensions of QLF seek to capture and balance objective measures of income, living conditions, education or health, with subjective measures such as an individual's appreciation of their living environment, how safe they feel, or whether they can rely on friends/family [19].
Despite previous comments, there has been surprisingly little research on the evaluation of the influence of smart dimensions on the QLF, as it is the main expected outcome of embedded smart technologies for cities and citizens into the urban space. Therefore, the second research question of this research is:

RQ2. How can the different smart dimensions influence the citizen's QLF in SCs?.

In brief, this paper seeks to fill the gap of the research regarding the possible association between the SCs phenomenon and the level of QLF in the urban environment. Concretely, this paper analyzes whether the new wave of SCs impact on a higher QLF in the urban environment and how this impact is produced, analyzing how the smart dimensions could have an influence on the higher level of the QLF in SCs. To achieve this aim, this paper collects information about the "smartness" of European cities and the widely used QLF rankings in order to test whether the label of SC, as well as, the type of smartness of the SC could be associated to a higher degree in the citizen's QLF.

The remainder of this paper is as follows. The next section makes some comments regarding the link between SCs and the increase of the citizen's QLF in the urban environment. In the third section of the paper, the empirical research is performed, describing the sample selection and the methodology of research. Then, the main results of our study are shown and, finally, the discussion and conclusion section bring the paper to an end.

\section{The Quality of Life in Smart Cities}

In the early 21 st century, the rapid transition to a highly urbanized population has lead cities and urban areas to be complex social ecosystems, where ensuring sustainable development and QLF have forced societies and their governments to make an intensive use of information and communication technologies (usually ICTs), as a way of solving the city's economic, social and environmental challenges. This new wave of the cities, called SCs, puts ICTs to the forefront emphasizing not only the technology itself but also its role in human, social capital and the usage of these technologies as the way to become a city smart [3], and the solutions of social and economic problems to which SCs have to face, shall, in the end, have a significant influence on the QLF as enjoyed by the city's' residents [15].

In this regard, in this paper, an SC is identified based on the European Union definition, as "a place where traditional networks and services are made more efficient with the use of digital and telecommunication 
technologies, for the benefit of its inhabitants and businesses" [19], and it has the potential to improve the QLF through social innovation and the creation of more inclusive, sustainable and connected cities for the potential benefit of their inhabitants, public administrations and businesses [19]. In fact, the concept of SC is strongly linked to urban planning's commitment to QLF of its citizens [16, 23] through the delivery of smart services [26] aiming to improve the living environment of citizens [32, 41], what gives citizens a leading role as main requestors of public services and fundamental actors of citizen participation [51]. In fact, recent research has also confirmed a significant positive relationship between QLF and citizen participation [13].

The QLF is, therefore, the broader goal in SC, but it is often linked not only to smart initiatives in a strict sense but also more generally to all the policies of the local government [16]. This way, an SC from the governmental aspect can be seen as an urban strategy aiming at improving QLF in the city, safeguarding the environment and reaching economic development at the same time [3]. This issue demands a reconsideration of planning processes, the implementation of new governance models [45], the analysis of the relationships between politicians and public managers, and the creation of internal cultures that encourage all public servants to see the world from the citizen's perspective [1].

In this regard, a meaningful assessment method of the smart city governance should measure individual well-being and satisfaction in the city in a comparable and dynamic way through the impacts of public policies on the QLF of the citizens (something that goes beyond the mere outputs or services provided) [13] since the QLF indexes are considered as tools for measuring long-term public value creation [6], which is a very complex goal [3]. Indeed, QLF information can provide invaluable insights for mayors, governors, developers, and other organizations involved in city planning to address fundamental questions like, "How can we improve?", "What does our city look like compared to neighboring cities?", and so on, which allows these organizations to better target the criteria that are most important to them. City rankings about SCs and QLF are relevant here because they generate discussion and debate on smartness, competitiveness, and QLF, helping to rethink formerly elaborated strategies and development priorities. Therefore, the link between SC rankings and QLF rankings seems to be a strong link that should be analyzed.

Also, the QLF research should be then at the front and center in this process of evaluating people's relationship to their environment within the city [30] and QLF metrics should be seriously factored into any smarter strategy [49]. Indeed, a study carried out in Spain found that citizens consider QLF improvement and public services quality as the main utilities of smart cities [14]. Nonetheless, traditionally, aggregated macroeconomic figures have been used in order to track the progress of societies, but it oversimplifies the problem [13]. In addition, the QLF has been viewed as part of the profile of a 'competitive city' too and has been employed by city agencies to make their location attractive to different global capital, which has emphasized place characteristics instead of adopting other groups' views of QLF [46]. So, it is unsurprising that the QLF indexes be relevant to complement macroeconomic figures with socio-economic figures summarizing welfare in society, although measuring the QLF of the citizens is far from being an easy task, being especially at the city level where the information of QLF is still not very well developed [13].

In brief, the SCs are envisioned as creating a better and more sustainable city because people's QLF is improved through a more livable environment and stronger economic prospects [32]. This way, the SC phenomenon promises the increase of public value providing citizens an increasing participation in public affairs [43] with the aim at making citizen-centric decisions and improving their QLF through the intensive use of ICTs [53]. Thus, this paper analyzes whether the SCs have achieved their main outcome getting a higher QLF in the urban environment. Also, this paper analyzes the 'smart' source of the QLF and the influence that the different aspects of smart governance could have on greater levels of QLF. To achieve this aim, in the next section of this paper, we perform an empirical research in the European SCs looking for their position in relevant QLF rankings and investigating the influence of the different smart dimensions on the citizen's perceptions of QLF.

\section{Empirical Research}

\subsection{Sample selection}

This paper is based on the European setting because the European integration process has reduced differences in economic, social and environmental standards and norms providing a common market, which makes cities more similar in their preconditions [26]. The data collection method of this paper is based on two different sample groups of cities. The first one is composed of the European cities labeled "smart" by a European project sponsored by Asset One Immobilienentwicklungs AG. This paper is focused on largesized SCs (cities from 300,000 to 1 million inhabitants) included in the version 4.0 of the project because large 
and dense cities are highly productive and innovative due to a highly urbanized population that creates many challenges for the planning, design, finance, construction, governance, and operation of urban infrastructure and services [28] which impacts on a higher QLF for their inhabitants [29, 27].

This selection method provides an instrument for effective learning processes regarding urban innovations in specific fields of urban development (http://www.smart-cities.eu) and ranks SCs based on more than 30 factors, grouped into 6 characteristics [25]: smart economy, smart people, smart governance, smart mobility, smart environment, and smart living. The objective of a ranking is not only specified by its aim and its target audience but also by its spatial scope and the desired factors and indicators behind the ranking [26] and its main utility is to support planning, city benchmarking and intercity comparisons [11]. This phase of our sample selection process collects $88 \mathrm{SCs}$ to the sample selection.

The second group of sample cities is composed of those European cities considered as "Non-smart cities" (NSCs). This second group is difficult to be selected because a city is labeled "smart" when actions towards innovation in management, technology, and policy are taken [39]. Hence, every city could attain a different level of smartness within a range, rather than falling in "black and white" categories of smartness or not. Nonetheless, while the adoption of up-to-date technologies does not guarantee the success of smart city initiatives, Nam \& Pardo [39] and EU [19] argue that technology is obviously a necessary condition for a smart city.

Therefore, in our paper, other 88 European cities have been selected which, according to the criteria indicated above, are not labeled "SCs". To achieve this aim, we have avoided both those cities listed in the European project mentioned before and those that are members of the EUROCITIES network (see http://www.eurocities.eu/), which is composed of the local governments of the main European cities that are working actively to become smart to increase their QLF using ICTs in the city.

In a first stage, to obtain a homogenous sample, the sample cities labeled "SCs" have been sorted by country, and then the same number of NSCs has been selected from each one of these European countries (88 NSCs in total). These selected NSCs have the highest population (once removing those labeled as "smart") since dense cities tend to become smart. In a second stage, this selection process removes the NSCs with a population under 300,000 inhabitants with the aim of using the same criteria as that used for cities classified as SC. Therefore, the total number of NSCs in this paper reduces to 12 . This way, our final sample selection, following the previously mentioned selection process, consists of a total of 100 European cities (88 SCs and 12 NSCs).

\subsection{Data and Method}

Data collection method in this paper is based on the connection between sample SCs and NSCs and the QLF of their citizens. The measurement of QLF is a complex task due to the multidimensional aspect of the QLF concept which is based on objective data and/or on subjective citizen's perception [20, 15]. So, this research collects data from four different relevant QLF rankings, two of them -EUROSTAT and NUMBEO ${ }^{1}$ based on the citizen's feelings or perceptions (participative rankings), and two others -MERCER and $\mathrm{EIU}^{2}$ - based on the measurement of different quantitative dimensions that encompass the QLF ranking (non-participative rankings).

Nonetheless, although the difference between the two methods of measuring the QLF is clear, Kaklauskas et al. [31] have recently demonstrated that the obtained values of such criteria have revealed a good level of congruity between the ranks obtained by employing the different methods and data have been proved to be similar -little difference between these methods for city ranking were found-.

All QLF rankings used in our research are referenced to 2015 since it is the last year in which all of them have been published simultaneously, although some of them are already updated. Descriptive statistics and graphical methods are used to show the position of the different sample cities in the QLF rankings with the aim at answering RQ1.

Regarding RQ2, this research has been based on a question the EUROSTAT ranking regarding the satisfaction of citizens with their life into their city (SL) and its link with the score that this city has obtained in the European project sponsored by Asset One Immo-bilienentwicklungs AG (mentioned previously) on each one of the six smart dimensions or characteristics that an SC could have. To achieve this aim, hypothesis testing using multiple linear regression models (MLR) have been performed. The proposed MRL model for RQ2 is, the following:

1

http://ec.europa.eu/regional policy/sources/docgener/studies/pdf/urb an/survey 2015 en.pdf and https://www.numbeo.com/quality-oflife/region rankings.jsp?title $=2015 \&$ region $=150$, respectively.

See https://www.imercer.com/uploads/GM/qol2015/h5478qol2015/index $\underline{\text { html }}$ and http://media.heraldsun.com.au/files/liveability.pdf, respectively. 
$\mathrm{SL}_{\mathrm{i}}=\beta 0+\beta 1 * \mathrm{~S}-$ Economy $_{\mathrm{i}}+\beta 2 * \mathrm{~S}-$ People $_{\mathrm{i}}+\beta 3 * \mathrm{~S}-$ Governance $_{i}+\beta 4 *$ S-Mobility $y_{i}+\beta 5 *$ S-Environment $t_{i}+$ $\beta 6$ *S-Living

Where SL is the proportion of persons who are satisfied living in their city and S-Economy, S-People, S-Governance, S-Mobility, S-Environment and SLiving are the scores obtained for each one of the sample SCs in each one of these smart dimensions in the European project mentioned before (version 4.0).

Although the total number of sample cities in our research is 100, not all of them appear in all the selected QLF rankings. Nonetheless, the use of all these QLF rankings could provide great objectivity to the data collected in our study limiting the influence that particular criteria used could have on these QLF rankings. Thus, the 30,49\% of the total European cities included in the EUROSTAT ranking (25 cities out of 82 indexed European Cities), the $29,82 \%$ of the total European cities included in the MERCER ranking (17 cities out of 56 indexed European Cities), the 30,56\% of the total European cities included in the EIU ranking (11 cities out of 36 indexed European Cities), and the $41,38 \%$ of the total European cities included in the NUMBEO ranking (24 cities out of 58 indexed European Cities) are included in the sample selection.

\section{Analysis of Results}

\subsection{RQ1. How is the transition possible from the objective measures of city smartness to an intangible entity of QLF?.}

Table 1 in Annex shows the QLF ranking characteristics regarding the range of cities in each one the quartiles of the rankings as well as the number of European cities included into each one of the rankings. In this regard, while European cities are mainly concentrated on the Q1 and Q2 of the non-participative rankings (MERCER and EIU), they are equally distributed into the different quartiles in the participative QLF rankings (EUROSTAT and NUMBEO). Therefore, results indicate differences between objective measures and citizen's perceptions of QLF, which could mean the existence of a gap between outcomes and the impact that these outcomes could have on the citizen's perceptions of the QLF.

On the other hand, table 2 in Annex shows the descriptive statistics of the data and collects the position that sample SCs and NSCs get on each one of the QLF rankings. To begin with, sample selection of our study represents, at least, the $30 \%$ of the European cities indexed in the QLF rankings, which means that the sample selection of this research allows us to obtain significant findings for future research. In addition, all sample cities included in the QLF rankings are labeled "SCs". Indeed, NSCs are not present in any of the selected QLF rankings. This result could indicate that the smartness of a city can produce higher QLF.

On the other hand, results in table 2 in Annex indicate that sample SCs are mainly present in the subjective QLF rankings in which they represent more than the $25 \%$ of all sample SCs. Indeed, whereas 25 and $24 \mathrm{SCs}$ are present in the QLF rankings of EUROSTAT and NUMBEO, only 17 or 11 SCs are ranked in the best positions in the QLF rankings of MERCER and EIU.

Nonetheless, although the highest number of sample SCs is concentrated on the best quartiles of all the QLF rankings, it is especially true in QLF rankings based on objectives indicators. In fact, almost all sample SCs are concentrated in the Q1 and Q2 in the QLF rankings of MERCER and EIU. By contrast, these sample SCs are dispersed into the different quartiles in the QLF rankings of EUROSTAT and NUMBEO -see table 2 in Annex-. This result seems to confirm the existence of a gap between objective measures of the citizen's QLF and their perceptions regarding this matter.

Finally, results obtained in the median scores of the sample SCs in table 2 in Annex confirm that median scores of the sample SCs are below the limit of the Q1 values in the MERCER and EIU rankings, whereas median scores of sample SCs fit within the range of values of the second quartile or in the third quartile of the EUROSTAT and NUMBEO rankings.

In a more detailed analysis of the cities, we can also appreciate graphically the findings in Figure 1 in Annex. In this figure, we can observe the position of each one of the sample SCs and NSCs in the selected QLF rankings as well as the quartiles in each of the rankings.

\subsection{RQ2. How can the different smart dimensions influence the citizen's QLF in SCs?}

The MLR model is applied to find the statistically significant independent variables to predict citizen's perceptions about their satisfaction of living in their city. The summary of MLR results is displayed in table 3 in Annex. The value of R2 is approximately 0,77, which is good enough. Independence analysis indicates that the Durbin-Watson test is over 1,5. Therefore, the constructs used are independent.

Also, collinearity analysis is performed using SPSS software. According to our results, tolerance analysis shows that all values obtained for the constructs are over 0,5 -see table 3 in Annex-, which means that the probability of multicollinearity is low. In fact, the higher tolerance scores, the lower multiple correlations 
[22]. Furthermore, Variance inflation factors (VIF) for all independent variables are low and under 2 , which again implies that the multicollinearity is low.

Results show that smart economy, smart mobility, and smart living are the most important constructs in the citizen's perceptions about their satisfaction of living in their city (p-value under 0,05). Nonetheless, the impact of the smart environment on the QLF is very low (see the coefficient value) and the smart economy seems to show a negative influence on the citizen's perception of QLF.

Also, the dimension of smart people seems also to be a good construct for increasing the citizen's perception of QLF (p-value close to 0,1 ). By contrast, the smart governance and the smart environment are not significant constructs for increasing the citizen's perceptions of QLF.

\section{Discussions and Conclusions}

This paper is focused on SCs and their potential for improving the citizen's QLF. Indeed, a great promise brought with the growth of SCs is the improvement of the QLF of their citizens through the intensive use of ICTs and the implementation of new governance models for improving citizen involvement in public decisions.

Based on a sample SCs and NSCs in the European context, this paper provides insights about two main research questions about the relationship between SCs and QLF: a) the existence of a link between SCs and higher QLF; and b) the link between smart dimensions and citizen's perceptions of QLF.

Findings indicate that the promise of the advent of SCs for increasing the QLF seems to be true. In fact, results show that only sample SCs are those ranked in the QLF rankings. NSCs do not appear in any of the QLF rankings used in this study.

In addition, this finding is clearer and more consistent in the results obtained in the selected objective QLF rankings. Indeed, results show that sample SCs are better ranked in objective QLF rankings than in subjective QLF rankings. The main question here is: are there other different aspects in the city different from their intensive use of ICTs that could have the same impact on the citizen's perception of QLF in the city?. So, future research could analyze this issue in a different context to obtain significant findings.

On the other hand, this research has also analyzed whether smart dimensions, defined and scored by a European project [26], have an impact on the citizen's perception of QLF. In this regard, findings indicate that smart economy, smart mobility, and smart living are the smart dimensions with a higher significant impact on the citizen's perception of QLF. Nonetheless, the smart environment seems not to have a high influence on the citizen's perception of QLF and the smart economy seems to have a negative influence on it.

This finding seems to be different for particular national settings of European countries. This way, for example, a previous study focused on Spain [14] indicates that the smart environment is also a factor that could have an impact on citizen's perception of QLF. So, future research could analyze the aim of this paper in different national settings in identifying trends according to some variables like administrative culture, political settings, e-participation models and so on.

In addition, recent research has demonstrated that university students perceive a poor preoccupation of the municipality in the areas of smart economy and smart governance [51]. This negative perception could explain why the public policies of the city management in smart economy practices are not valued by citizens as a piece of their QLF. Perhaps higher government transparency could help to overcome this negative perception.

Also, although prior research on SCs advocates new and open governance models, our findings indicate that smart governance does not have an impact on the citizen's perception of QLF. This finding confirms recent research in which, paradoxically, smart governance was the factor that university students less associated with QLF [51]. Therefore, our findings have not been able to demonstrate that although collaborative and participative models of governance are the preferred models of governance for practitioners [53, 43, 44], these new models can have a positive impact on citizen's perception of QLF.

In this regard, future research should investigate whether citizens are promoted and ready to participate in city management as well as the incentives they have to cooperate with local governments in the city management. Also, city governments could allocate financial resources to improving a culture of open participation in the city and to making information and technological tools available to citizens for increasing their participation in public affairs. So, future research should focus its attention on the components that could help citizens to change their perception regarding smart governance and its link with the increase of the QLF in the city.

Finally, our findings indicate that smart living is the most significant dimension for influencing the citizen's perception of QLF. This finding confirms recent research in which respondents to a questionnaire recognized smart living as one of the most valued dimensions for their QLF. [51]. As the smart living dimension is a very broad concept, future research 
should analyze the components that have a higher impact on the citizen's perception of QLF (culture and leisure facilities, health conditions, housing quality, and so on).

In brief, SCs seem to fill the expectations of citizens to increase their QLF. Nonetheless, citizen's perceptions of higher QLF seem to be based on both the outcomes achieved in the city and their impact on their lives. In this regard, perhaps the knowledge that citizens have on the concept of SCs and their dimensions could be seriously questioned [14]. It could influence their perception regarding the smart dimensions and their contribution to increasing their QLF perception. This way, future research could also analyze this issue to understand better the components of the citizen's perceptions of QLF and how city governments in SCs can implement public policies to increase this perception.

\section{References}

[1] Albert, A., and E. Passmore, Public Value and Participation [electronic Resource]: A Literature Review for the Scottish Government, Scottish Government, Edinburgh, 2008. Available at: https://www.gov.scot/resource/doc/216076/0057753.pdf (August 2018).

[2] Allwinkle, S., and P. Cruickshank, "Creating smart-er cities: An overview", Journal of urban technology, 18, 2, Taylor \& Francis, London, 2011, pp. 1-16.

3] Barsi, B., "Beyond indicators, new methods in Smart city assessment", Smart Cities and Regional Development (SCRD) Journal, 2, 1, National University of Political Studies and Public Administration, Bucharest, 2018, pp. 8799.

[4] Bătăgan, L., "Smart cities and sustainability models", Informatica Economică, 15, 3, INFOREC Association, Bucharest, 2011, pp. 80-87.

[5] Batty, M. "Cities in disequilibrium", In Non-Equilibrium Social Science and Policy (pp. 81-96). Springer International Publishing, Switzerland, 2017.

[6] Benington, J., "From private choice to public value", In Public value: Theory and practice (pp. 31-49), Macmillan International Higher Education, 2011.

[7] Bettencourt, L. M., J. Lobo, D. Helbing, C. Kühnert, and G. B. West, "Growth, innovation, scaling, and the pace of life in cities", in Proceedings of the national academy of sciences, 104, 17, 2007, pp. 7301-7306.

[8] Boivard, T., and E. Loeffler, "From Engagement to Coproduction: The Contribution of Users and Communities to Outcomes and Public Value", VOLUNTAS: International Journal of Voluntary and Nonprofit Organizations, 23, 4, Springer Netherlands, Amsterdam, 2012, pp. 1119-1138.

[9] Bryson, J. M., B. C. Crosby, and L. Bloomberg, "Public value governance: Moving beyond traditional public administration and the new public management", Public Administration Review, 74, 4, John Wiley \& Sons Inc., Medford, 2014, pp. 445-456.
[10] BSI (British Standards Institution), PAS181:2014: Smart City Framework - Guide to Establishing Strategies for Smart Cities and Communities. BSI Standards Publication, BSI Standards Limited, London, 2014. Available at: http://www.bsigroup.com/en-GB/smart-cities/Smart-CitiesStandards-and-Publication/PAS-181-smart-cities-framework (August 2018).

[11] Caird, S. P., and S. H. Hallett, "Towards evaluation design for smart city development", Journal of Urban Design, Taylor \& Francis, London, 2018, pp. 1-22.

[12] Camagni, R., and R. Capello, "Second-rank city dynamics: Theoretical interpretations behind their growth potentials", European Planning Studies, 23, 6, Taylor \& Francis, London, 2015, pp. 1041-1053.

[13] Cárcaba, A., E. González, J. Ventura, and R. Arrondo, "How Does Good Governance Relate to Quality of Life?", Sustainability, 9, 4, MDPI, Basel, 2017, pp. 631-646.

[14] Centre of Innovation of the Public Service and IE Business School, Smart cities. La transformación digital de las ciudades, Centre of Innovation of the Public Service and IE Business School, Madrid, 2015.

[15] Cunha Rodrigues, J. P., "Local Government Aimed at Quality of Life in Sustainable Cities", In Entrepreneurial, Innovative and Sustainable Ecosystems (pp. 35-53). Springer, Cham, 2018.

[16] Dameri, R. P. "Searching for smart city definition: a comprehensive proposal", International Journal of Computers \& Technology, 11, 5, Ciworld, Punjab, 2013, pp. 2544-2551. [17] Dameri, R.P. and C. Rosenthal-Sabroux, Smart City. How to Create Public and Economic Value with High Technology in Urban Space, Springer International Publishing, Switzerland, 2014.

[18] Douglas, S., and A. Meijer, "Transparency and Public Value-Analyzing the Transparency Practices and Value Creation of Public Utilities", International Journal of Public Administration, 39, 12, Taylor \& Francis, London, 2016, pp. 940-951.

[19] European Union (EU), Urban Europe. Statistics on cities, towns and suburbs. 2016 Edition. European Union, Luxembourg, 2016.

[20] EUROSTAT, Quality of life indicators - measuring quality of life, Luxembourg, 2018. Available at: at http://ec.europa.eu/eurostat/statisticsexplained/index.php/Quality_of_life_indicators_measuring_quality_of_life (January 2018).

[21] Feeney, M. K., and A. Brown, "Are small cities online? Content, ranking, and variation of US municipal websites", Government Information Quarterly, 34, 1, Elservier, Amsterdam, 2017, pp. 62-74.

[22] Field, A., Discovering statistics using IBM SPSS statistics, Sage Publications Ltd, London, 2013.

[23] Fontana, F., "The smart city and the creation of local public value", In Smart City (pp. 117-137), Springer International Publishing, Switzerland, 2014.

[24] Gagliardi, D., Schina, L., Sarcinella, M. L., Mangialardi, G., Niglia, F., and A. Corallo, "Information and communication technologies and public participation: interactive maps and value added for citizens", Government Information Quarterly, 34, 1, Elservier, Amsterdam, 2017, pp. 153-166. 
[25] Giffinger, R., and H. Gudrun, "Smart cities ranking: an effective instrument for the positioning of the cities?", ACE: Architecture, City and Environment, 4, 12, UPCommons, Barcelona, 2010, pp. 7-26.

[26] Giffinger, R., C. Fertner, H. Kramar, R. Kalasek, N. Pichler-Milanovic, and E. Meijers, Smart cities. Ranking of European medium-sized cities, Final Report, Centre of Regional Science, Vienna UT, 2007.

[27] Glaeser, E. L., Triumph of the city: How our greatest invention makes us richer, smarter, greener, healthier, and happier, The Penguin Press, USA, 2012.

[28] Harrison, C., and I. A. Donnelly, "A theory of smart cities", in Proceedings of the 55th Annual Meeting of the ISSS-2011, 55, 1, Hull, UK, 2011.

[29] Jacobs, J., The death and life of great American cities, Random House, New York, 2016.

[30] Jeffres, L. W., C. C. Bracken, G. Jian, and M. F. Casey, "The impact of third places on community quality of life", Applied Research in Quality of Life, 4, 4, Springer Netherlands, Amsterdam, 2009, pp. 333-345.

[31] Kaklauskas, A., E. K. Zavadskas, A. Radzeviciene, I. Ubarte, A. Podviezko, V. Podvezko, A. Kuzminske, A. Banaitis, A. Binkyte, and V. Bucinskas, "Quality of city life multiple criteria analysis", Cities, 72, Elservier, Amsterdam, 2018, pp. 82-93.

[32] Lee, J. H., M. G. Hancock, and M. C. Hu, "Towards an effective framework for building smart cities: Lessons from Seoul and San Francisco", Technological Forecasting and Social Change, 89, Elservier, Amsterdam, 2014, pp. 80-99.

[33] Lowndes, V., L. Pratchett, and G. Stoker, "Local Political Participation: The Impact of Rules-in-Use", Public administration, 84, 3, John Wiley \& Sons Inc., Medford, 2006, pp. 539-561.

[34] Makkaoui, M., F. Lachhab, and M. Bakhouya, "University-Based Smart Cities: from collective intelligence to smart crowd-conscience", The Journal of Quality in Education, 7, 9, AMAQUEN, 2017. Available at: 〈http://journal.amaquen.org/index.php/joqie/article/view/10> . (August 2018).

[35] Meijer, A., and M. P. Rodríguez Bolívar, "Governing the smart city: a review of the literature on smart urban governance", International Review of Administrative Sciences, 82, 2, Sage Publications Ltd, London, 2016, pp. 392-408.

[36] Moore, M. H., Creating public value: Strategic management in government, Harvard University Press, Cambridge, 1995.

[37] Moore, M. H., Recognizing public value, Harvard University Press, Boston, 2013.

[38] Moore, M. H., Public Value: Of, By, and For the People. An Analytic Note for a Webinar Presented on June 28, 2017. Available at: https://www.hks.harvard.edu/sites/default/files/HKSEE/HKS EE\%20PDFs/20170821 RPV\%20Webcast\%20Analytic\%20 Note.pdf. (August 2018).

[39] Nam, T., and T. A. Pardo, "Conceptualizing smart city with dimensions of technology, people, and institutions", in Proceedings of the 12th annual international digital government research conference: digital government innovation in challenging times, ACM, 2011, pp. 282-291.
[40] Pereira, G. V., M. A. Macadar, E. M. Luciano, and M. G. Testa, "Delivering public value through open government data initiatives in a Smart City context", Information Systems Frontiers, 19, 2, Springer Netherlands, Amsterdam, 2017, pp. 213-229.

[41] Piro, G., I. Cianci, L. A. Grieco, G. Boggia, and P. Camarda, "Information centric services in smart cities", Journal of Systems and Software, 88, Elservier, Amsterdam, 2014, pp. 169-188.

[42] Rodríguez Bolívar, M. P., "Characterizing the role of governments in smart cities: A literature review", In Smarter as the new urban agenda (pp. 49-71), Springer International Publishing, Switzerland, 2016.

[43] Rodríguez Bolívar, M. P., "Governance Models and Outcomes to Foster Public Value Creation in Smart Cities", Scienze Regionali, 17, 1, Associazione Italiana di Scienze Regionali , Milano, 2018, pp. 57-80.

[44] Rodríguez Bolívar, M. P., "Creative Citizenship: The New Wave for Collaborative Environments in Smart Cities", Academia Revista Latinoamericana de Administración, 31, 1, Emerald Publishing, Bingley, 2018, pp. 277-302.

[45] Rodríguez Bolívar, M. P., "Governance in Smart Cities: A Comparison of Practitioners' Perceptions and Prior Research", International Journal of E-Planning Research (IJEPR), 7, 2, IGI Global, Hershey, PA, 2018, pp. 1-19.

[46] Rogerson, R. J., "Quality of life and city competitiveness", Urban studies, 36, 5-6, Sage Publications Ltd, London, 1999, pp. 969-985.

[47] Sherman, H., M. Weinberg, and M. Lewis, Measuring public value creation, Voinovich Center for Leadership and Public Affairs, Ohio, 2002.

[48] Stockholm, (2006), Stockholmforsoket, Facts and Results from the Stockholm Trial, Stockholm. Available at: http://www.stockholmsforsoket.se/upload/Hushall_eng.pdf. (August 2018).

[49] Thorne, C., and C. Griffiths, "Smart, smarter, smartest: Redefining our cities", In Smart City (pp. 89-99), Springer International Publishing, Switzerland, 2014.

[50] Tranos, E. and D. Gertner, " Smart networked cities?", Innovation: The European Journal of Social Science Research, 25, 2, Taylor \& Francis, London, 2012, pp. 175190.

[51] Vázquez, J. L., A. Lanero, P. Gutiérrez, and C. Sahelices, "The Contribution of Smart Cities to Quality of Life from the View of Citizens" In Entrepreneurial, Innovative and Sustainable Ecosystems (pp. 55-66), Springer, Cham, 2018.

[52] Williams, I., and H. Shearer, "Appraising public value: Past, present and futures", Public Administration, 89, 4, John Wiley \& Sons Inc., Medford, 2011, pp. 1367-1384.

[53] Yeh, H., " The effects of successful ICT-based smart city services: From citizens' perspectives", Government Information Quarterly, 34, 3, Elservier, Amsterdam, 2017, pp. 556-565 
ANNEX: TABLES

Table 1. Characteristics of QLF rankings

\begin{tabular}{|c|c|c|c|c|c|c|c|c|c|c|c|}
\hline & & \multicolumn{5}{|c|}{ The range of cities in each quartile } & \multicolumn{5}{|c|}{ Number of European cities in the selected QLF rankings } \\
\hline & & Total & Q1 & Q2 & Q3 & Q4 & Q1 & Q2 & Q3 & Q4 & Total \\
\hline \multirow{2}{*}{$\begin{array}{l}\text { Objective } \\
\text { rankings }\end{array}$} & MERCER & 230 & $1-57$ & $58-114$ & $115-172$ & $173-230$ & 31 & 18 & 4 & 4 & 57 \\
\hline & EIU & 140 & $1-35$ & $36-70$ & $71-105$ & $106-140$ & 18 & 12 & 4 & 2 & 36 \\
\hline \multirow{2}{*}{$\begin{array}{c}\text { Subjective } \\
\text { rankings }\end{array}$} & EUROSTAT & 82 & $1-20$ & $21-41$ & $42-62$ & $63-82$ & 20 & 21 & 21 & 20 & 82 \\
\hline & NUMBEO & 58 & $1-14$ & $15-28$ & $29-42$ & $43-58$ & 14 & 14 & 14 & 16 & 58 \\
\hline
\end{tabular}

Source: Own elaboration.

Table 2. Descriptive statistics

\begin{tabular}{|c|c|c|c|c|c|c|c|c|c|c|c|c|c|c|c|c|}
\hline & & \multirow{2}{*}{\multicolumn{15}{|c|}{ Smart cities }} \\
\hline & & & & & & & & & & & & & & & & \\
\hline & & \multirow{2}{*}{ Frequency } & \multirow{2}{*}{$\begin{array}{l}\text { Relative frequency } \\
\text { over sample SCs }\end{array}$} & \multicolumn{4}{|c|}{$\begin{array}{l}\text { Frequency in Qi position } \\
\text { in the QLF ranking }\end{array}$} & \multicolumn{4}{|c|}{$\begin{array}{l}\text { Relative frequency over Qi position of } \\
\text { total European Cities in the QLF ranking }\end{array}$} & \multirow[t]{2}{*}{ Median } & \multirow[t]{2}{*}{ Standard deviation } & \multirow[t]{2}{*}{ Min } & \multirow[t]{2}{*}{$\operatorname{Max}$} & \multirow[t]{2}{*}{ Range } \\
\hline & & & & $\mathrm{Q}_{1}$ & $\mathrm{Q}_{2}$ & $\mathrm{Q}_{3}$ & $\mathrm{Q}_{4}$ & $\mathrm{Q}_{1}$ & $\mathrm{Q}_{2}$ & $\mathrm{Q}_{3}$ & $\mathrm{Q}_{4}$ & & & & & \\
\hline \multirow{2}{*}{$\begin{array}{l}\text { Objective } \\
\text { rankings }\end{array}$} & MERCER & 17 & $19,32 \%$ & 11 & 6 & 0 & 0 & $35,48 \%$ & $33,33 \%$ & - & - & 40 & 33,72 & 6 & 99 & 93 \\
\hline & EIU & 11 & $12,50 \%$ & 6 & 4 & 1 & 0 & $33,33 \%$ & $33,33 \%$ & $25,00 \%$ & - & 33 & 20,37 & 10 & 72 & 62 \\
\hline \multirow{2}{*}{$\begin{array}{l}\text { Subjective } \\
\text { rankings }\end{array}$} & EUROSTAT & 25 & $28,41 \%$ & 8 & 5 & 8 & 4 & $40,00 \%$ & $23,81 \%$ & $38,10 \%$ & $20,00 \%$ & 41 & 24,11 & 4 & 81 & 77 \\
\hline & NUMBEO & 24 & $27,27 \%$ & 7 & 8 & 7 & 2 & $50,00 \%$ & $57,14 \%$ & $50,00 \%$ & $12,50 \%$ & 23 & 13,77 & 2 & 52 & 50 \\
\hline
\end{tabular}

Source: Own elaboration.

Table 3. MLR: coefficients and independence and collinearity analysis

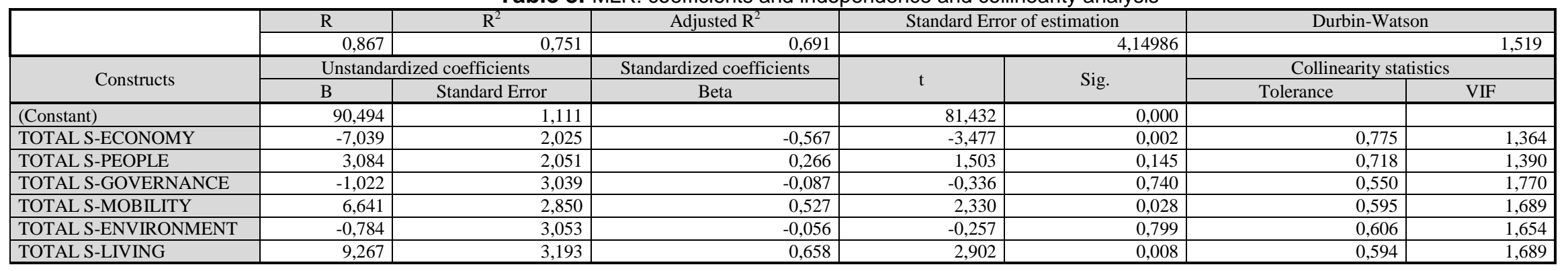


MERCER

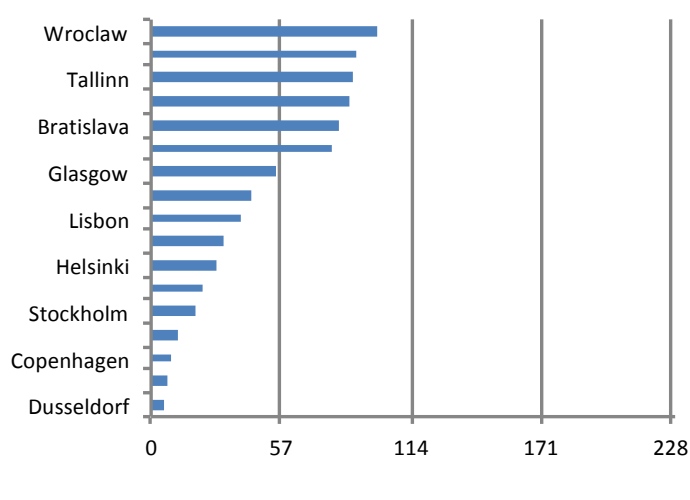

EUROSTAT

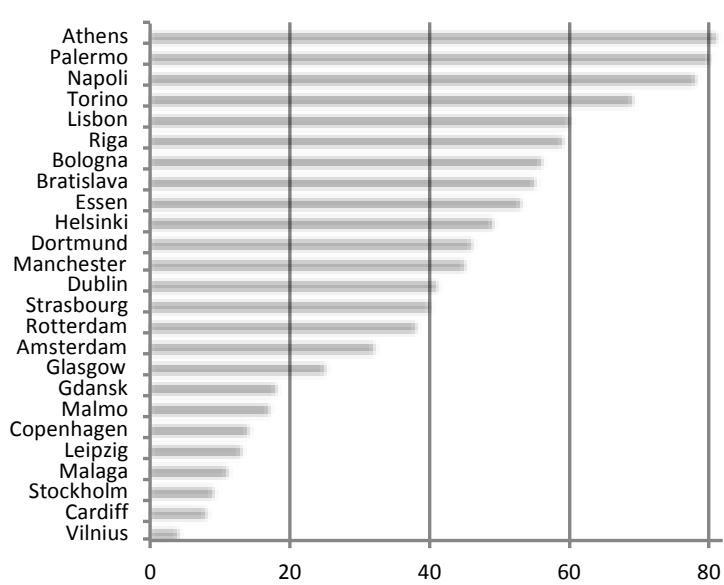

EIU
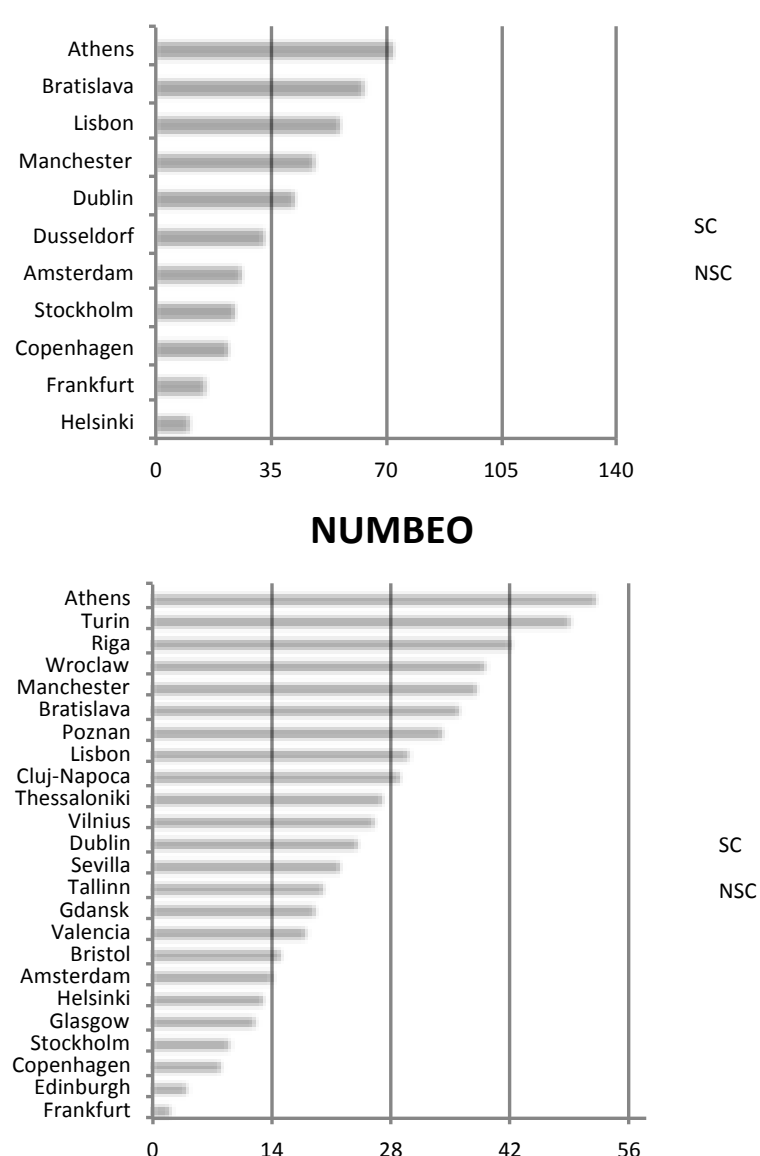

Figure 1. Objective and Subjective QLF Rankings - How is the transition possible from the objective measures of city smartness to an intangible entity of quality of life? 